\title{
Surgical Strategy for Dermoid and Epidermoid Tumors of the Posterior Fossa - Experience with 21 Patients
}

\section{Melhor estratégia cirúrgica para tumores dermoides $e$ epidermoides da fossa posterior - experiência em 21 pacientes}

José Carlos Lynch ${ }^{1}$ Leonardo C. Welling ${ }^{2}$ Antonio Aversa ${ }^{3}$ Celestino Esteves ${ }^{1}$ Jânio Nogueira ${ }^{3}$ Mariângela Gonçalves ${ }^{1}$ Hélio Lopes ${ }^{1}$

${ }^{1}$ Neurocirurgia, Hospital Federal Servidores do Estado do Rio de Janeiro, Rio de Janeiro, RJ, Brazil

2 Neurocirurgia, Universidade Estadual de Ponta Grossa,

Ponta Grossa, PR, Brazil

${ }^{3}$ Neurocirurgia, Instituto Nacional do Câncer/INCA, Rio de Janeiro, RJ, Brazil
Address for correspondence Leonardo C. Welling, MD, PhD, Universidade Estadual de Ponta Grossa, Ponta Grossa, Paraná, Brazil (e-mail: leonardowelling@yahoo.com.br).

Arq Bras Neurocir 2017;36:145-152.

\section{Abstract \\ Keywords \\ - dermoid tumor \\ - epidermoid tumor \\ - intracranial tumor \\ - microsurgery \\ - posterior fossa}

\section{Resumo}

Objective The aim of this paper is to describe our surgical strategy and technique and to identify the best management for posterior fossa dermoid and epidermoid tumors (PFDETs).

Methods We retrospectively identified 21 consecutive patients (11 males and 10 females), with a mean age of 33.2 years, a mean follow-up of 6.1 years, and pathologically confirmed PFDETs. Total 17 patients were submitted to the extended retrosigmoid approach. This approach incorporates transverse sigmoid sinus exposure and a generous mastoidectomy.

Results Gross total tumor removal was achieved in $16(76.1 \%)$ cases, with no surgical mortality and a recurrence rate of $9.5 \%$.

Conclusions The surgical strategies used in this group of patients enabled the total removal of most tumors without surgical mortality and with minimal morbidity and recurrence rates. The extended retrosigmoid approach used is an alternative path regarding cranial base approaches. This approach is quick, simple and safe, and decreases the retraction of the cerebellum.

Objetivos O objetivo deste estudo é descrever a técnica operatória para a melhor abordagem dos tumores dermoides e epidermoides da fossa posterior.

Métodos Foram analisados retrospectivamente 21 pacientes (11 masculinos e 10 femininos), com idade média de 33,2 anos e acompanhamento de 6,1 anos, com diagnóstico histopatológico de tumor dermoide ou epidermoide de fossa posterior. received

May 19, 2017

accepted

August 1, 2017

published online

August 23, 2017
DOI https://doi.org/

10.1055/s-0037-1606292. ISSN 0103-5355.
Copyright (e 2017 by Thieme Revinter

Publicações Ltda, Rio de Janeiro, Brazil
License terms

(ㄷ) (i) $\ominus$ (5) 


\author{
Palavras-chave \\ - tumor dermoide \\ - tumor epidermoide \\ - tumor intracraniano \\ - microcirurgia \\ - fossa posterior
}

Nesse grupo, 17 pacientes foram submetidos a abordagem retrossigmoide estendida. Esta abordagem inclui exposição do seio transverso e sigmoide, além de ampla mastoidectomia.

Resultados Remoção cirúrgica total foi alcançada em 16 (76,1\%) casos sem mortalidade e com recidiva em $9,5 \%$ dos casos.

Conclusões As abordagens cirúrgicas utilizadas nesta série permitiram a ressecção total na maioria dos pacientes, sem mortalidade cirúrgica e com morbidade e recorrência mínima. A craniotomia retrossigmoide estendida utilizada é uma boa alternativa para abordagens da base do crânio. É uma abordagem simples, rápida, segura, e que minimiza a retração do cerebelo.

\section{Introduction}

Intracranial dermoid and epidermoid tumors (IDETs) are congenital, slow-growing tumors that develop between the 3rd and 5th weeks of gestation from ectodermal remnants during neural tube formation in embryogenesis. Epidermoid tumors are lined by a delicate capsule of stratified squamous epithelium, while dermoid tumors include, in addition to skin, many hair follicles, as well as sebaceous and sweat glands. ${ }^{1-3}$ These tumors are rare, comprising around $1 \%$ to $2 \%$ of all intracranial tumors. ${ }^{1-14}$ The cerebellopontine angle (CPA) constitutes the place of $7 \%$ to $9 \%$ of all tumors. $5,7,9,10,15-21$ Despite the development of microsurgery and cranial base techniques, the surgical management of posterior fossa dermoid and epidermoid tumors (PFDETs) continues to be a formidable technical challenge to neurosurgeons, because these tumors grow in close contact with neural and vascular structures that cannot be sacrificed or retracted. A controversial debate has continued for several years, which has not been completely settled to date. Should the neurosurgeon promote gross total removal (GTR) of the tumor, which can result in unwarranted cranial nerve $(\mathrm{CN})$ deficit and/or arterial injury, or should GTR be avoided, and a safer, subtotal removal (STR) of the tumor be performed instead? Traditionally, CPA lesions are treated through a retrosigmoid approach. While these operative corridors are sufficient in most cases, they still only provide a limited angle of view. Compared with the classical retrosigmoid approach, the extended retrosigmoid approach allows for greater visualization and operative space within the posterior fossa. ${ }^{22-25}$

The objectives of the current paper are to report on our operative strategy and surgical technique, and to identify the best operative management for PFDETs.

\section{Methods}

\section{Data Collection}

This study included 21 consecutive patients with PFDETs who underwent surgery between January 1986 and January 2014 at the Department of Neurosurgery of three different institutions in Rio de Janeiro, Brazil. The main authors (JCL and AA) performed the majority of the surgeries. The medical charts, pre- and postoperative imaging, and pathological reports of the patients were retrospectively reviewed to ascertain the diagnosis of PFDETs, thereby creating a database from which information pertinent to the present study was collected. The intraoperative videos and/or photos of 14 patients were analyzed for nuances of the microsurgical technique. Informed consent was waived due to the retrospective character of the study. Computed tomography (CT) and magnetic resonance imaging (MRI) scans were reviewed with the Radiology Department (-Figs. 1-3 [1 A, 2A and $\mathbf{3}]$ ). Control postoperative imaging studies were performed within the first 48-72 hours after surgery to document the extent of the resection and postoperative changes (-Fig. 1E and 2D). The first clinic visit occurred $\sim 15$ days after hospital discharge, with subsequent
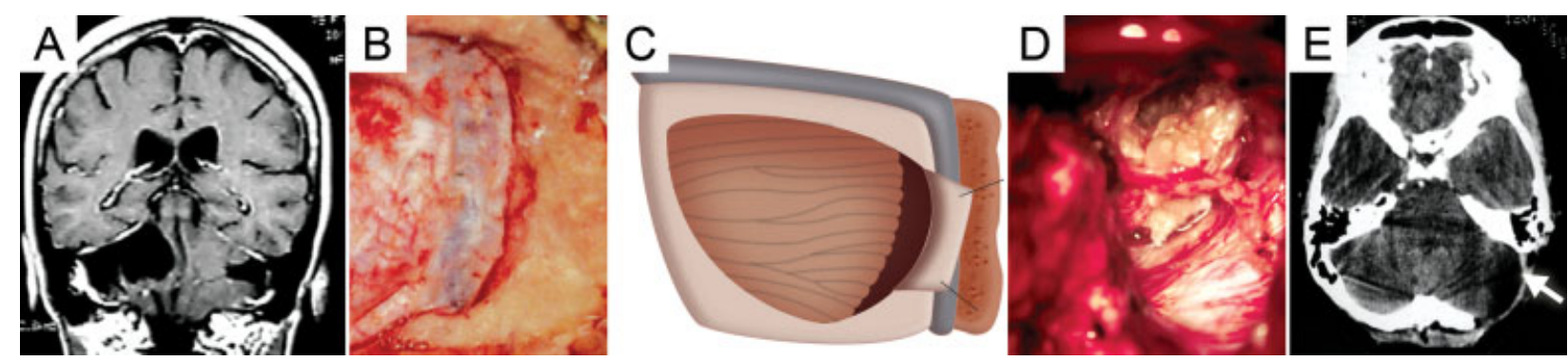

Fig. 1 (A) Coronal T1-weighted MRI image revealing CPA hypointense lesion with brainstem compression and contralateral shift. (B) Operative view showing a wide mastectomy and complete skeletonization of the SS. (C) The dura mater is opened with the base toward the midline, stay sutures elevated the SS and father further increase the access to the CPA. (D) Microphotograph after the extended retrosigmoid approach demonstrates that the tumor filled the CPA and engulfed most of the neurovascular structures. (E) Immediate postoperative CT: observe the extension of the mastectomy creating a flat corridor to the CPA (arrow). 


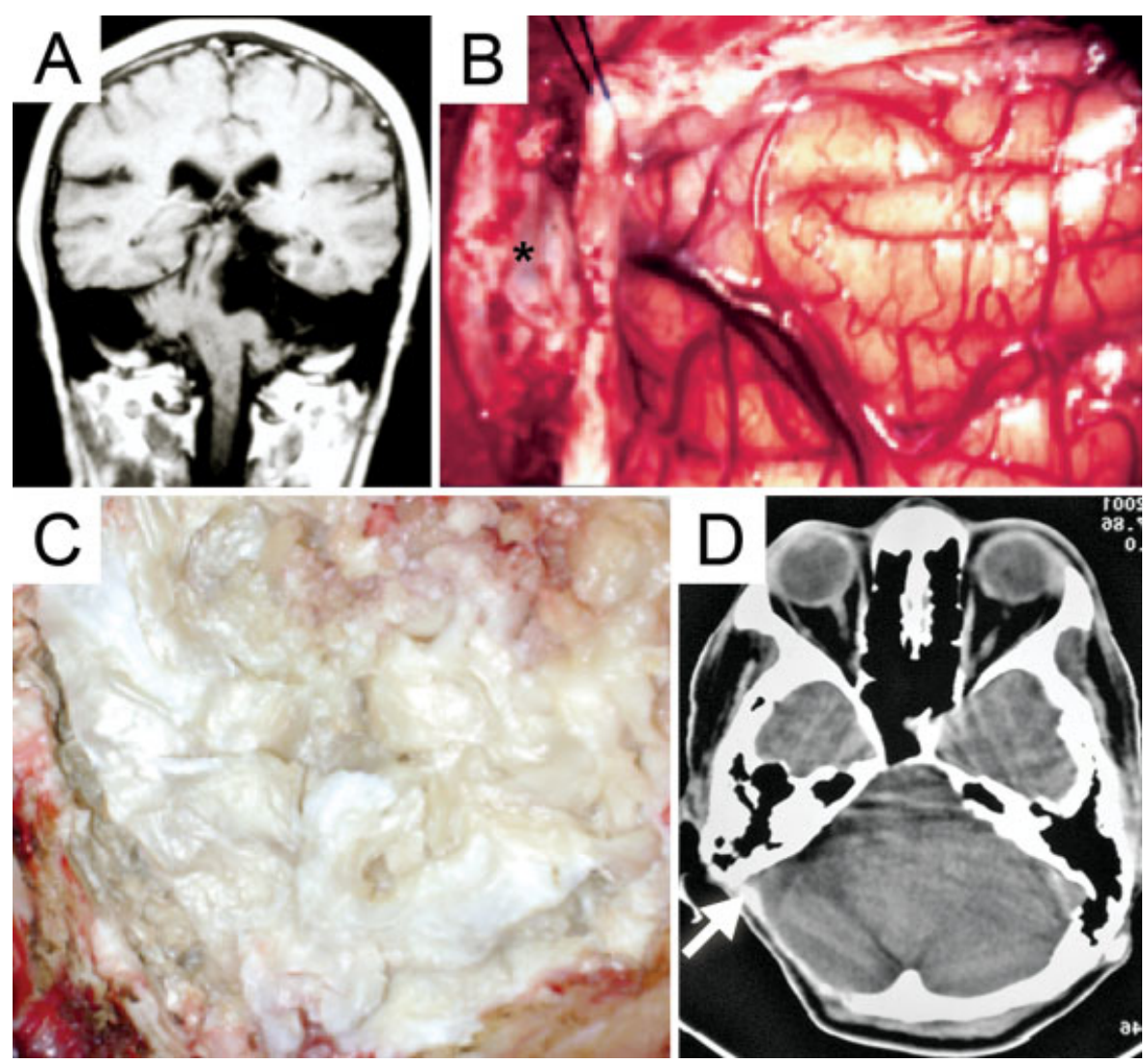

Fig. 2 (A) Coronal T1-weighted MRI showing a large mass lesion in the left CPA that extends to the hiatus incisura. (B) Operative photograph of a patient in semi-sitting position showing the extended retrosigmoid craniectomy with skeletonization of the SS (asterisk). (C) After elevation of the left cerebellar hemisphere, the large epidermoid tumor came clearly into view in the operative corridor. (D) A postoperative CT scan reveals GTR and the generous mastectomy, and a flat corridor to the CPA (arrow).

visits at 2 and 6 months. After that, the patients were scheduled for revision at one-year intervals. They were contacted for imaging studies and clinic visits, or interviewed by telephone. In this series, three recently introduced innovations were used: neurophysiological monitoring, endoscopy, and neuronavigation. The Glasgow Outcome Scale (GOS) defined the outcome.

\section{Neurosurgical Approaches and Microsurgery Technique for Lesions Situated in the cerebellopontine angle}

We used a tailored surgical approach to manage each case: a) CPA tumors were removed via a suboccipital retrosigmoid or an extended approach, depending on the size and extension of the tumor; b) vermian and fourth-ventricular lesions were operated through a midline suboccipital craniotomy. Considering that IDETs situated in the CPA are the most challenging to remove, we describe in details our surgical technique to manage 15 (71.4\%) IDETs located in the CPA.

\section{Patient Positioning}

Under endotracheal general anesthesia, most patients were placed in a semi-sitting position, with the head flexed forward and secured in the Mayfield three-point fixation device (Integra LifeSciences Holding Corporation, Plainsboro, NJ, US). The semi-sitting position enables natural cerebellar relaxation via gravity without the need for lum- bar drainage. Some patients, however, were placed in dorsal decubitus with contralateral head rotation and ipsilateral shoulder elevation (surgeon's preference). An arterial line and a central venous catheter were placed in all patients. The patients were secured with a large tape in the operating table to allow table rotation to the right or to the left, and elevation or tilt of the head. These simple maneuvers, associated with multiple microscope angulations, enhance the exposure, expanding the operative field. The involved region was shaved, prepped, and draped in a sterile fashion. Routine antibiotics, dexamethasone, and mannitol were used. The procedure was initiated with the utilization of a 2.5x surgical loupe and co-axial lighting for soft tissue incision and bone work.

\section{Skin Incision and Muscle Dissection}

A $10-\mathrm{cm}$ vertical linear incision was made $2-3 \mathrm{~cm}$ medially to the mastoid and centered $\sim 2 \mathrm{~cm}$ above the mastoid tip. The incision went down through the galea and periosteum over the suboccipital bone and the posterior border of the sternocleidomastoid and trapezius muscles, proceeding to the level of C2. Emissary veins that opened during the subperiosteal dissection were controlled using bipolar coagulation and waxed immediately, with repeated waxing at the end of the surgery. The spinous process of the 2 nd cervical vertebra was the palpatory bony landmark guide to the position of the 


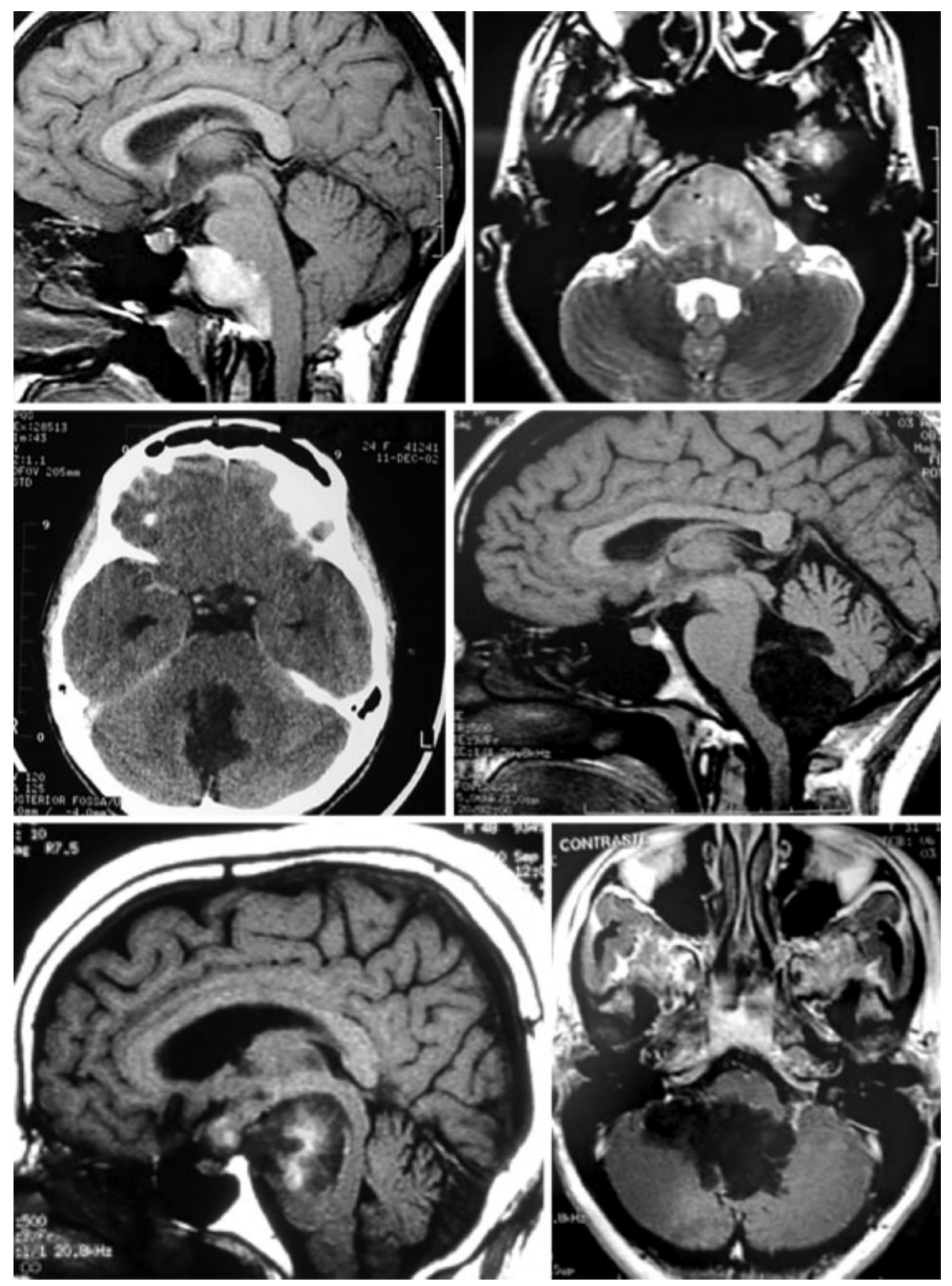

Fig. 3 MRI and CT scan in cases of PFDETs found in this series.

foramen magnum, and enabled a safe subperiosteal dissection of the suboccipital region to be performed along the posterior $\mathrm{C} 1 \mathrm{arch}$. The paravertebral muscles were detached from the occipital bone squama and progressively sectioned with a scalpel. A self-retaining retractor was gradually inserted into the wound, thus exposing the suboccipital triangle and maintaining the paravertebral muscles in the appropriate position. At that point, the posterior arch of $\mathrm{C} 1$ was identified.

\section{Craniectomy}

The retrosigmoid craniectomy is performed unilaterally using a high-speed drill with a cutting burr. The overlying bone is reduced to the thickness of an eggshell, then a burr hole is drilled just inferior to the junction of the transverse sinus (TS) and sigmoid sinus (SS). The craniectomy extended medially $\sim 5 \mathrm{~cm}$. A regular Leksell rongeur is used to enlarge the craniectomy from the posterior edge of the occipital condyle to the inferior edge of the TS, exposing the lateral edge of the SS. In the case of large, giant or multicompartment tumors, we perform the extended retrosigmoid approach: the dura mater is dissected bluntly from the inner surface of the sub-occipital squama; at that moment, the rongeuring crosses the SS and comes to within almost a centimeter of the jugular bulb. After the SS has been thoroughly exposed (skeletonizing), the mastoid process is rongeured generously away, permitting a far lateral exposure. If the meningioma extends to the foramen magnum (FM), the FM and the posterior arch of $\mathrm{C} 1$ are removed. The piece removed from the bone thinned by a drill is the safest method of exposure of the SS. The access achieved provides a direct, parallel and unobstructed view of the petrous ridge, 
providing sufficient midline and lateral exposure of the tumor. Emissary veins can produce brisk bleeding; the hemostasis is obtained with the help of bipolar coagulation or with hemostatic sponges. The operating microscope is brought to the surgical field and the operation proceeds with magnification, which ranges from $10 \mathrm{X}$ to $20 \mathrm{X}$.

\section{Opening the Dura}

The dura mater is opened by a horseshoe-shaped incision with its base toward the midline. Two relaxing incisions are made laterally, one to the TS and the other to the SS. The dural edges are tented up and rotate anteriorly with the SS out of the bone margins and down over the cut surface of the mastoid. The arachnoid of the cisterna magna is incised, and the cerebrospinal fluid (CSF) is allowed to drain spontaneously. The combination of bone removal, dural opening, and CSF drainage provides excellent visualization of the entire CPA, with minimal cerebellar retraction.

\section{Exposing the Lesion}

The tumor was then visualized under the arachnoid as a bright white mass. The exposure was improved after a gentle elevation of the cerebellum, which was maintained in position with fixed retractors. The arachnoid attachments along the cerebellum in the cerebellopontine cistern were opened, and the arachnoid membrane enveloping the tumor was incised in the posterior aspect of the exposed area using micro scissors. Then, the arachnoid membrane was gently dissected away from the tumor surface to the sides using microsurgery instruments. The arachnoid membrane was left intact to protect the brainstem from surgical dissection. At that point, the high magnification provided by the operating microscope proved particularly beneficial. Although IDETs are soft and usually poorly vascularized lesions, thorough hemostasis was obtained throughout the procedure using bipolar forceps to keep the field bloodless.

\section{Debulking the Tumor}

After low-current bipolar coagulation under saline irrigation of a few fine vessels travelling on the tumor surface, the lesion was incised, penetrated, and progressively debulked from within, mobilized, and removed in piecemeal fashion. Careful attention is paid to identifying and preserving the arachnoid plane at the tumor-brainstem interface, which facilitated complete tumor resection and minimized small vessel, $\mathrm{CN}$ and brainstem injuries.

\section{Dissecting the Tumor}

As the surgery proceeded within the space provided by the progressive tumor debulking, the DET was dissected and mobilized away from the facial, acoustic and trigeminal nerves, the brainstem, and blood vessels by gentle, meticulous microsurgical techniques. We used, at that point, fine micro scissors and several types of angled dissectors in addition to multiple microscope angulations at varying magnifications. As tumor debulking proceeded, the brainstem progressively relaxed and provided additional working space for dissection. When dealing with large lesions that compress and deform the brainstem, these tumors should be dissected from, and not against, the brainstem and CNs. The lesion was mobilized and, once rid of adhesions, removed from the surgical field with cupped forceps; small fragments were sucked away with the aid of irrigation. The surgeons should be aware that CNs and vessels are usually engulfed by the tumor; these delicate structures should be carefully dissected and spared. The aspiration is performed in a soft suction mode during the microsurgical dissection to avoid injuries to those fragile structures. Gross total tumor removal is always attempted, but whenever the dissection of the tumor from the basilar and vertebral arteries, their perforating branches, the brainstem, or CNs could entail risk of damage, we left a thin rim of tumor tissue attached to those structures. In case of supratentorial tumor extension, the lesion would be resected through the ipsilateral corridor as much as possible, and the remnant would be followed for any symptomatic or radiological growth. With recent advances in neuroendoscopic techniques, reports of endoscopic-assisted and purely endoscopic removal of CPA epidermoid tumors have emerged. The endoscope is a useful adjunct to the microscope in facilitating additional inspection and further resection of PFDETs. In this series, the endoscopic-assisted techniques were only employed on two occasions. During the operation, copious irrigation is provided, and cotton pads are placed around the exposed area to reduce the spillage of irritating cyst content into the subarachnoid space. Inspection of the tumor bed with the operating microscope is then performed for verification of the extent of tumor resection. Before closure, the patient's blood pressure is brought to a normotensive level for at least 10-15 minutes and monitored for risk of oozing. The dura is closed primarily or with a free pericranial graft. The craniectomy defect is covered with a paste made of bone dust and a few drops of blood and normal saline. All open mastoid cells are sealed with bone wax to prevent CSF leaks. The superficial planes are closed in three layers using interrupted nylon sutures. Postoperatively, all patients are cared for at an intensive care unit before returning to the ward.

\section{Illustrative Case}

A 68-year-old woman developed progressive gait ataxia, diplopia, left-ear deafness, and a left facial paresis that lasted for two years. An MRI scan showed a tumor located in the left-side CPA with brainstem distortion and contralateral shift (-Fig. 1A). The patient was placed in a semi-sitting, position and the extended retrosigmoid approach was achieved (-Fig. 1B and C). The tumor occupied the entirely left CPA and engulfed most of the neurovascular structures. After STR, the $7^{\text {th }}$ and $8^{\text {th }}$ CNs were preserved, and the brainstem, decompressed (-Fig. 1D). A postoperative CT scan showed the extent of the mastoidectomy ( $\mathbf{- F i g}$. 1E). The recovery was slow, but the patient eventually achieved a GOS score of 3 .

\section{Results}

\section{Patient Demographics and Clinical Characteristics}

Since this is a retrospective study, it has inherent biases and drawbacks that only a multicenter, prospective study could 
Table 1 Characteristics of 21 patients treated for PFDETs

\begin{tabular}{|c|c|c|}
\hline & $\mathbf{n}$ & $\%$ \\
\hline \multicolumn{3}{|l|}{ Age at treatment } \\
\hline \multicolumn{3}{|c|}{$1-78$ years (mean: 32.4 years) } \\
\hline \multicolumn{3}{|l|}{ Gender } \\
\hline Male & 11 & $52.3 \%$ \\
\hline Female & 10 & $47.6 \%$ \\
\hline \multicolumn{3}{|l|}{ Location } \\
\hline CPA & 17 & $80.9 \%$ \\
\hline Cerebellar & 4 & $19.0 \%$ \\
\hline \multicolumn{3}{|c|}{ Neurological Presentation } \\
\hline Elevated ICP & 9 & $42.8 \%$ \\
\hline CN deficits & 9 & $42.8 \%$ \\
\hline Gait disturbance & 8 & $38.0 \%$ \\
\hline Visual deficit & 4 & $19.0 \%$ \\
\hline Trigeminal neuralgia & 3 & $14.2 \%$ \\
\hline \multicolumn{3}{|l|}{ Pathology } \\
\hline Epidermoid & 17 & $80.9 \%$ \\
\hline Dermoid & 4 & $19.0 \%$ \\
\hline Gross total removal & 16 & $76.1 \%$ \\
\hline \multicolumn{3}{|l|}{ Follow-up } \\
\hline \multicolumn{3}{|c|}{ 1-23 years (mean: 6.1 years) } \\
\hline Surgical mortality & 0 & $0 \%$ \\
\hline Recurrence & 3 & $14.2 \%$ \\
\hline GOS 4 or 5 & 14 & $66.6 \%$ \\
\hline
\end{tabular}

Abbreviations: CN, cranial nerve; CPA cerebellopontine angle; GOS, Glasgow Outcome Sclae; ICP, intracranial hypertension; PFDETs, posterior fossa dermoid and epidermoid tumors.

overcome. Twenty-one patients with PFDETs were identified. At the time of diagnosis, the patients' average age was 32.4 years, ranging between 1 and 78 years. In our study, 11 (52.3\%) patients were male, and 10 (47.6\%) were female. The neurological symptoms and signs vary according to tumor location and extension of the lesion. The demographics, neurological presentation, and results are summarized in -Table 1 .

\section{Neuroimaging}

All patients underwent a CT and/or an MRI scan. In general, the tumors appeared as low-density lesions on plain CT. The MRI revealed that, in the majority of the cases, the lesion was hypointense on T1-weighted and hyperintense on T2-weighted images, similarly to the MRI appearance of arachnoid cysts. When available, the differential diagnosis was solved on inspection of the diffusion-weighted images (DWIs), which showed the epidermoid tumors to be distinctly bright compared with arachnoid cysts and other tumors. The DWI is the best MRI sequence to diagnose and follow-up these lesions.

One tumor appeared as a high-intensity signal on T1, and as a mixed-intensity signal on T2. Five (22.7\%) lesions showed irregular enhancement after contrast injection. Two (9.5\%) of them revealed calcifications. (-Fig. 1A and 1B)

\section{Mortality, Morbidity, Extension of Resection, and Recurrence}

We used a tailored surgical approach to manage each case: a) from total 17 CPA tumors, for 11 patients, due to the large size or extension of the lesions, we chose the extended retrosigmoid approach. In other 6 individuals with smaller tumors, a conventional retrosigmoid approach was performed; b) vermian and fourth ventricular lesions were operated upon through a midline suboccipital craniectomy. There was no operative mortality until 30 days after surgery, but 2 elderly patients with CPA lesions died from pulmonary complications at the 90th and 210th postoperative days. The follow-up period ranged from 1 to 21.5 years (mean: 7.2 years). Two patients were lost to follow-up. The dissection of the adherent capsule from the $6^{\text {th }}, 7^{\text {th }}$, and $8^{\text {th }} \mathrm{CNs}$ led to transient abducens and facial nerve palsies, as well as permanent hearing loss, in 7 patients. Eight patients had hearing deficits before surgery; none of them improved after surgery. Most facial nerve palsies recovered after a few months. Two pediatric patients with fourth ventricle tumors developed transient difficulty in swallowing. Temporary postoperative complications, including wound infection, CSF fistulas that needed reoperation, deep venous thrombosis, and pulmonary complications occurred in 5 (22.7\%) patients.

We achieved GTR in 16 (76.1\%) patients, and STR in 5 (23.8\%), and surgeon impression and/or postoperative imaging confirmed all. Fourteen (66.6\%) patients achieved GOS scores of 4 or 5 .

\section{Discussion}

\section{Mortality and Morbidity}

Many studies ${ }^{7-11,14,15,19,21,26-28}$ have reported that the clinical symptoms vary among patients depending on tumor location, ranging from slight $\mathrm{CN}$ deficits to severe ataxia, $\mathrm{CN}$ dysfunction, and brainstem compression, as we observed in this series (-Table $\mathbf{1}$ ). Since the advent of microsurgical techniques, several series have shown that PFDETs can be surgically resected with a good outcome..$^{4,12,17,20,28,29}$ Samii et $\mathrm{al}^{12}$ revealed that operative morbidity and mortality from PFDET removal had declined remarkably in the past 20 years. Before the advent of the operating microscope, the operative mortality ranged from $20 \%$ to $57 \%$. Contemporary series have reported zero or low operative mortality $4,12,15,19,20,28,30$ (-Table 2). Notwithstanding, complications have been described. 4,12,15,16,20,21 Aseptic meningitis is reported to be a common cause of postoperative morbidity. Two patients developed a postoperative CSF leakage that needed reoperation to close the fistula. In this current series, there was no surgical mortality.

\section{Extension of Resection Dilemma and Recurrence}

Yasargil et al, ${ }^{4}$ Samii et al, ${ }^{12}$ and other authors ${ }^{7,15,27,30,31}$ advocate that the ideal management of PFDETs is GTR. However, GTR could be dangerous for some patients and 
Table 2 Contemporary surgical series on posterior fossa dermoid and epidermoid tumors

\begin{tabular}{|c|c|c|c|c|c|}
\hline Authors/Year & $\begin{array}{l}\text { Number } \\
\text { of cases }\end{array}$ & $\begin{array}{l}\text { MORT } \\
(\%)\end{array}$ & $\begin{array}{l}\text { GTR } \\
\text { (\%) }\end{array}$ & $\begin{array}{l}\text { REC } \\
(\%)\end{array}$ & $\begin{array}{l}\mathrm{F} / \mathrm{U} \\
\text { (years) }\end{array}$ \\
\hline Berguer et al ${ }^{17} / 1985$ & 13 & 0 & 0 & 7.6 & 4.6 \\
\hline De Souza et a $1^{19} / 1989$ & 30 & 3.7 & 18 & 14.8 & 9 \\
\hline Yasargil et al ${ }^{4} / 1989$ & 43 & 0 & 95.4 & 0 & 5.2 \\
\hline Lunardi et $\mathrm{al}^{8} / 1990$ & 17 & 12 & 35 & 17.6 & 9 \\
\hline Vinchon et $\mathrm{al}^{21} / 1995$ & 9 & 22.2 & 0 & $\mathrm{~N} / \mathrm{A}$ & 3 \\
\hline Samii et al $\left.\right|^{12} / 1996$ & 40 & 2.5 & 75 & 7.5 & 5.7 \\
\hline Mohanty et al ${ }^{20} / 1997$ & 25 & 8 & 48 & 0 & 3.5 \\
\hline Talacchi et al ${ }^{15} / 1998$ & 28 & 3.5 & 57 & 30 & 8.6 \\
\hline Kobata et al ${ }^{28} / 2002$ & 30 & 0 & 56.7 & 6.6 & 11.4 \\
\hline $\begin{array}{l}\text { Lynch et al/2017 } \\
\text { (present study) }\end{array}$ & 21 & 0 & 76 & 9 & 7.2 \\
\hline
\end{tabular}

Abbreviations: $F / U$, follow-up; GTR, gross total removal; MORT, mortality; N/A, not avaible; REC, recurrence.

difficult to achieve because these tumors can be critically located, and there may be adherence or even encasement of vital structures by the tumor. $5,7,8,10,15-17,20,21$ Because PFDETs "flow" into any available subarachnoid space, slowly increase their volume and conform to the shape of the cavities they enter, CNs and arteries can be engulfed or displaced by the tumor. On diagnosis, many PFDETs are already large or giant, and frequently have extended into multiple anatomic compartments. For these reasons, many authors recommend that GTR should be avoided to decrease mortality and morbidity. ${ }^{15-17,19-21,28,29}$ In our series, three CPA tumors spread along the cisterns of the posterior fossa and became partially trapped between the pons and the anteriorly displaced vertebrobasilar arteries, enveloping the perforating branches, and densely adhering to the brainstem. We performed a careful dissection at higher magnification to prevent injury of the fragile perforating vessels that were engulfed by the tumor. However, even a delicate dissection could entail the risk of damaging these perforating vessels, which could provoke profound and permanent neurological disabilities. We cautiously left a rim of tumor attached to those structures (STR). In case those tumors had extended into multiple anatomic compartments, the lesion would be resected through the ipsilateral corridor as much as possible, and the contralateral or supratentorial remnant would be followed for any symptomatic or radiological growth.

To preserve the function of the 7th and 8th nerves, we took several careful steps during the surgery:

1. The preservation of the auditory artery branch is requisite if the hearing is to be maintained.

2. Sharp dissection with micro scissors is used for the dissection of the tumor from the nerves, the use of bipolar coagulation is kept to a minimal necessary, and when used, the coagulation is done in small segments between the forceps tips under a stream of normal saline, with a low current, to prevent heating damage.
3. The aspiration is regulated in the soft module, and a suction tip can be used without fear of damaging a nerve or vascular structures.

4. The dissection of the meningioma from the $7^{\text {th }}$ and $8^{\text {th }}$ nerves should be performed from medial to lateral, avoiding traction under the fragile cochlear nerve in the meatus.

5. After the removal of the lesion, if there is slight ooze under the facial nerve, a hemostatic agent should be used instead of the bipolar coagulation.

6. Drilling the posterior wall of the IAC to remove intracanalicular fragments is performed with a $2.5-\mathrm{mm}$ burr under continuous irrigation, without damaging the neural structures.

The best surgical strategy for PFDETs has been debated for a long time. The controversy is underlined by one major question: how far can we go with the intent of achieving GTR? On the one hand, if the surgeon persists with any attempt to remove every last residual lesion to achieve the cure of the patient, it could result in an unwarranted $\mathrm{CN}$ or arterial injury, thus increasing mortality and morbidity. On the other hand, experience emphasizes that when tumors are removed incompletely, they tend to regrow after varying periods of time. As Sekhar and Wright ${ }^{30}$ point out, the next surgeon operating on the patient will be confronted with severe adhesions of blood vessels and CNs to the brain, and with the inability to remove the lesion entirely or nearly entirely. Because PFDETs are indolent, the risk of potential complications of GTR should be well weighed against the benefits. Consequently, GTR is not always a reasonable goal to achieve, especially in elderly patients. $^{7,8,10,12,16,17,20,21,25,28,29}$

Published papers on PFDETs have reported GTR rates ranging from $0 \%$ to $95.4 \% .4,7,8,10-12,14-16,20,21,29$ In the current series, we achieved GTR in $72.7 \%$ of the patients (- Table $\mathbf{1}$ ). Our surgical objective was always to prioritize the patient's quality of life; therefore, STR could represent a very acceptable goal in tumors encasing the basilar and vertebral arteries, or perforating vessels, or those adhering to CNs. Previous studies with long-term follow-up have reported an overall estimated recurrence rate ranging from $0 \%$ to $26 \%{ }^{8,10,11,13,15,19,29,31}$ In the present series, the recurrence rate was of $9 \%$ (3 cases).

The extended retrosigmoid approach, first described by Malis $\mathrm{L}^{23,24}$ and subsequently by other authors, ${ }^{25}$ is an excellent alternative approach to the classical retrosigmoid approach. In this approach, the SS is fully skeletonized, move lateral and superior by a dural tend suture, expanding the operative field to the CPA and deep vascular structures. A generous drilling of the mastoid air cells and skeletonizing the SS markedly increase the anterior exposure and decrease the amount of cerebellum retraction. It is particularly useful in cases of giant tumors that extend into the incisural notch or to the contralateral side. This approach is quick, simple, safe, and diminishes the amount of bone removal in comparison with the more radical, time-consuming skull base approaches. $^{23-25}$ There is a worry that the SS can be squeezed against the occipital bone and produce venous congestion and cerebral edema. If this happens, it will be 
necessary to relieve the traction on the SS. This complication was not observed in this series. We used the extended retrosigmoid approach in 11 patients with large, giant or multicompartment lesions. In 3 out of our 4 patients who had a supratentorial extension, the lesions could be entirely removed using this approach.

\section{Conclusion}

The neurosurgical management of PFDETs remains controversial, but our results allow us to conclude that the best surgical strategy is GTR. In cases of giant or multicompartment lesions, the extended retrosigmoid approach, which offers direct vision to the APC, reducing retraction to the cerebellum, is a good alternative. We achieved GTR in the majority of our patients without surgical mortality, and with low morbidity. However, GTR can be difficult to achieve because PFDETs can be critically located, with adherence to and involvement of vital structures. Our surgical objective was always to prioritize the patient's quality of life. Subtotal removal could represent a very acceptable goal in tumors encasing the basilar artery and perforating vessels or adhering to CNs. If the functional risk of GTR outweighs its potential benefits, an STR strategy should be adopted. Recurrence is rare after GTR, although a longer follow-up is required.

\section{References}

1 Zülch KJ. Brain tumors their biology and pathology. New York: Springer; 1965:240-245

2 Rubinstein LJ. Tumors of the nervous System. Washington. DC: Armed Forces Institute of Pathology; 1972:288-292

3 Russell DS, Rubinstein LJ. Pathology of Tumors of the Nervous System, ed 4. Baltimore: Williams \& Wilkins; 1977:29-32

4 Yaşargil MG, Abernathey CD, Sarioglu AÇ. Microneurosurgical treatment of intracranial dermoid and epidermoid tumors. Neurosurgery 1989;24(04):561-567

5 Grant FC, Austin GM. Epidermoids; clinical evaluation and surgical results. J Neurosurg 1950;7(03):190-198

6 Guidetti B, Gagliardi FM. Epidermoid and dermoid cysts. Clinical evaluation and late surgical results. J Neurosurg 1977;47(01):12-18

7 Schroeder HW, Oertel J, Gaab MR. Endoscope-assisted microsurgical resection of epidermoid tumors of the cerebellopontine angle. J Neurosurg 2004;101(02):227-232

8 Lunardi P, Missori P, Innocenzi G, Gagliardi FM, Fortuna A. Longterm results of surgical treatment of cerebello-pontine angle epidermoids. Acta Neurochir (Wien) 1990;103(3-4):105-108

9 Obrador S, Lopez-Zafra JJ. Clinical features of the epidermoids of the basal cisterns of the brain. J Neurol Neurosurg Psychiatry 1969;32(05):450-454

10 Rubin G, Scienza R, Pasqualin A, Rosta L, Da Pian R. Craniocerebral epidermoids and dermoids. A review of 44 cases. Acta Neurochir (Wien) 1989;97(1-2):1-16

11 Salazar J, Vaquero J, Saucedo G, Bravo G. Posterior fossa epidermoid cysts. Acta Neurochir (Wien) 1987;85(1-2):34-39
12 Samii M, Tatagiba M, Piquer J, Carvalho GA. Surgical treatment of epidermoid cysts of the cerebellopontine angle. J Neurosurg 1996;84(01):14-19

13 Ulrich J. Intracranial epidermoids. A study on their distribution and spread. J Neurosurg 1964;21:1051-1058

14 Yamakawa K, Shitara N, Genka S, Manaka S, Takakura K. Clinical course and surgical prognosis of 33 cases of intracranial epidermoid tumors. Neurosurgery 1989;24(04):568-573

15 Talacchi A, Sala F, Alessandrini F, Turazzi S, Bricolo A. Assessment and surgical management of posterior fossa epidermoid tumors: report of 28 cases. Neurosurgery 1998;42(02):242-251, discussion 251-252

16 Ahmed I, Auguste KI, Vachhrajani S, Dirks PB, Drake JM, Rutka JT. Neurosurgical management of intracranial epidermoid tumors in children. Clinical article. J Neurosurg Pediatr 2009;4(02):91-96

17 Berger MS, Wilson CB. Epidermoid cysts of the posterior fossa. J Neurosurg 1985;62(02):214-219

18 Cobbs CS, Pitts LH, Wilson CB. Epidermoid and dermoid cysts of the posterior fossa. Clin Neurosurg 1997;44:511-528

19 deSouza CE, deSouza R, da Costa S, et al. Cerebellopontine angle epidermoid cysts: a report on 30 cases. J Neurol Neurosurg Psychiatry 1989;52(08):986-990

20 Mohanty A, Venkatrama SK, Rao BR, Chandramouli BA, Jayakumar PN, Das BS. Experience with cerebellopontine angle epidermoids. Neurosurgery 1997;40(01):24-29, discussion 29-30

21 Vinchon M, Pertuzon B, Lejeune JP, Assaker R, Pruvo JP, Christiaens JL. Intradural epidermoid cysts of the cerebellopontine angle: diagnosis and surgery. Neurosurgery 1995;36(01):52-56, discussion 56-57

22 Sanai N, McDermott MW. A modified far-lateral approach for large or giant meningiomas of the posterior fossa. J Neurosurg 2010;112(05):907-912

23 Malis LI. Nuances in acoustic neuroma surgery. Neurosurgery 2001;49(02):337-341

24 Malis LI. Acoustic neuroma Surgery. Randolf: Codman; 1987:1-20

25 Quiñones-Hinojosa A, Chang EF, Lawton MT. The extended retrosigmoid approach: an alternative to radical cranial base approaches for posterior fossa lesions. Neurosurgery 2006;58(04, Suppl 2): ONS-208-ONS-214, discussion ONS-214

26 Gagliardi FM, Vagnozzi R, Caruso R, Delfini R. Epidermoids of the cerebellopontine angle (cpa): usefulness of CT scan. Acta Neurochir (Wien) 1980;54(3-4):271-281

27 Altschuler EM, Jungreis CA, Sekhar LN, Jannetta PJ, Sheptak PE. Operative treatment of intracranial epidermoid cysts and cholesterol granulomas: report of 21 cases. Neurosurgery 1990;26 (04):606-613, discussion 614

28 Kobata H, Kondo A, Iwasaki K. Cerebellopontine angle epidermoids presenting with cranial nerve hyperactive dysfunction: pathogenesis and long-term surgical results in 30 patients. Neurosurgery 2002;50(02):276-285, discussion 285-286

29 Gormley WB, Tomecek FJ, Qureshi N, Malik GM. Craniocerebral epidermoid and dermoid tumours: a review of 32 cases. Acta Neurochir (Wien) 1994;128(1-4):115-121

30 Talacchi A, Sala F, Alessandrini F, Turazzi S, Bricolo A. Assessment and surgical management of posterior fossa epidermoid tumors: report of 28 cases. Neurosurgery 1998;42(02):242-251, discussion 251-252 (Comments)

31 Sabin HI, Bordi LT, Symon L. Epidermoid cysts and cholesterol granulomas centered on the posterior fossa: twenty years of diagnosis and management. Neurosurgery 1987;21(06):798-805 